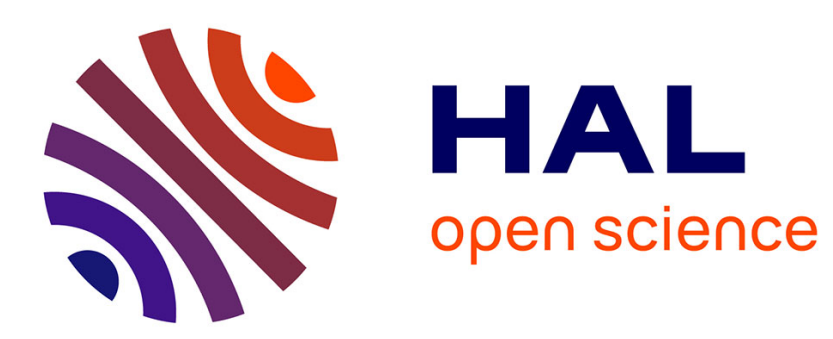

\title{
Femininities on transnational journeys and sexual health risk: experiences of Chinese immigrant women in Canada
}

Evelyne Micollier

\section{- To cite this version:}

Evelyne Micollier. Femininities on transnational journeys and sexual health risk: experiences of Chinese immigrant women in Canada. Gender, Place and Culture, 2017, 24 (12), pp.1787 - 1806. 10.1080/0966369X.2017.1400952 . hal-01681612

\section{HAL Id: hal-01681612 \\ https://hal.science/hal-01681612}

Submitted on 11 Jan 2018

HAL is a multi-disciplinary open access archive for the deposit and dissemination of scientific research documents, whether they are published or not. The documents may come from teaching and research institutions in France or abroad, or from public or private research centers.
L'archive ouverte pluridisciplinaire HAL, est destinée au dépôt et à la diffusion de documents scientifiques de niveau recherche, publiés ou non, émanant des établissements d'enseignement et de recherche français ou étrangers, des laboratoires publics ou privés. 
Femininities on transnational journeys and sexual health risk: experiences of Chinese immigrant women in Canada

\author{
Evelyne Micollier
}

To cite this article: Evelyne Micollier (2017) Femininities on transnational journeys and sexual health risk: experiences of Chinese immigrant women in Canada, Gender, Place \& Culture, 24:12, 1787-1806, DOI:10.1080/0966369X.2017.1400952

To link to this article: https://doi.org/10.1080/0966369X.2017.1400952

Published online: 16 Nov 2017.

Available online: http://www.tandfonline.com/10.1080/0966369X.2017.1400952

IRD (Institut de recherche pour le développement/French National Research Institute for Sustainable Development), IRD UMI 233, INSERM 1175, University of Montpellier

Contact : evelyne.micollier@ird.fr

CESSMA (Centre d'Etudes en Sciences Sociales/Centre for Social Sciences Studies in Africa, America, and Asia), IRD-University of Paris 7, INALCO, Paris

\title{
1787 Abstract
}

Negotiations at work in a globalising China in regard to femininity, sexuality, and family relationships have been well documented from the 1990s. Nonetheless less is known about them in a transnational context, and femininities are far less explored than masculinities. Drawing on interview data from a larger research study of transnationalism and gendered HIV vulnerability, this article investigates the intersection of femininity, sexuality and sexual health risk through Chinese immigrant women's narratives about their experiences in Canada. It examines to what extent these intimate negotiations within China are re-enacted through Chinese immigrant women's transnational experiences in Canada. These women live 'in-between' China and Canada in terms of identity, space and time with their cross-cultural connections unveiling both virtual and actual relations. Gender norms and roles, intimate and sexual experience, and family relations are realigned in the transnational lives of these women and are impacted by both their home and host societies, as well as their past and present experience in China. Used in the article as a concept and an analytical lens, gender is acknowledged as a key organising principle in postimmigration individual and social experience.

\section{Introduction}

In this article, femininity is understood as a gendered, discursive construction denoting a number of social processes and relationships in which the immediate reality of women's lives is embedded. Confronted to these dynamics, femininities form ever-evolving landscapes. Representations of femininity are unveiled through a range of discourses reflecting gender norms. These discourses and how they shape behaviours and practices provide a timely picture of femininity. Gender roles are observed in life experiences insightfully informing about the everyday life conditions of these women. 
Family relations, kinship systems, intimate and sexual relations, and relations between men and women, are domains in which gender roles and norms are highlighted. Through them the landscape of femininity is unfolded. In this article, transnationalism is considered as a situated 'place' reveal- ing moving 'spaces' produced by geographical and imagined individual journeys from one place to another. In their transnational journeys, transmigrating people are caught 'in between' spaces and times:

Migrants forge and sustain multi-stranded social relations that linked their societies of origin and settlement, [producing] the emergence of a social process in which migrants establish social fields crossing geographic, cultural, and political borders. Multiplicity of migrants' involvements in both the home and host societies is a central element of trans- nationalism. (Glick-Schiller, Basch, and Blanc-Szanton 1992, 1)

At a macro-social level, transnationalism refers to 'the conditions of cultural inter- connectedness and mobility across space which had been intensified under late capitalism' (Ong 1999, 4). Chinese immigrants in Canada live 'in-between' China and Canada, a specific form of transnational life in which 'they have maintained unprecedentedly close connections with their homeland' (Zhou 2017).

In this article, I use gender as a key analytical lens to examine the impacts of femininity on the experiences of Chinese skilled immigrant women to Canada, because gender remains a key concept for studying transnationalism (Ong 1999), and femininity is still underexplored in gender and migration studies (Winarnita 2016).

Are the hetero-normative sexuality and family relationships grounded in China's values and norms, prevalent and reproduced in a transnational context? The gen- der roles and norms reflected in the narratives of skilled Chinese immigrant women to Canada may or may not mirror the diversity of the Chinese societal landscape: shifts or continuities in these related to people's experiences of transnational life are shaped by both Canadian influences, and past and present life in China. Zhou (2012) emphasised actual changes in behaviour while reporting about a remaining silence around sex-related issues among those immigrants. This silence prevails mainly because of the conflict between behaviours and norms from the culture of origin with those they encounter in the new country.

While globally the feminisation of migration, with women outnumbering men, has been acknowledged since the 1990s (Castles and Miller 1993; Carling 2005; Yinger 2006), women mobilities are less explored. There were slightly more women of Chinese origin living in Canada than men: $51.7 \%$ of the Chinese community was female (Statistics Canada 2007). As Povinelli and George (1999, 443) observed, 'intimate and proximate spaces in which persons become subjects of embod- ied practices and times of desire' are much less mapped in globalisation studies than external social forms, namely flows, circulation of people, capital and culture, which are usually traced 'without any model of subjective mediation' (Povinelli and George 1999, 445). The article aims to examine sexual experiences and intimate and family relationships from a gendered perspective, a perspective which focuses on both 'experiencing' gender (gender roles and relations reflecting gender norms) 
and 'imagining' gender (narratives, meanings and cognitive aspects), namely 'vivre et penser le genre' (living and cognising gender) (Micollier 2012b, 177).

Femininity and HIV risk are better understood from gender approaches, as these take into account the ever-changing power dynamics produced by mobile people's engagements and the conditions of their post-immigration lives. A methodological implication is:

The need to identify the embeddedness of masculinities and femininities in the respec- tive context of sending and receiving societies ... [a theoretical consequence is] the need to integrate gender aspects into theories based on transnational migration, labour market, and network approaches. (Lutz 2010, 1658, 1659)

In China, adjustment to dramatic economic, social and cultural changes with simultaneous engagement in gender norms and roles grounded in Chinese cul- ture and history increased HIV risk in vulnerable groups but also in the population at large. In the mid-2000s, sexual transmission was officially acknowledged as the main route of HIV transmission. From the 2000s, a few surveys (UNAIDS 2001 and subsequent annual updates for China) and the first large-scale 'Knowledge Attitudes Behaviours Practices' survey (CHAMP 2008) about the situation in China, gave evidence of misperceptions and of relatively low to average HIV risk knowledge in the population. Gender norms and roles put both men and women at risk in regard to sexual activity, though not at the same level. While men engaging in high-risk behaviours can negotiate and exercise control over their sexual activities in line with their masculinity assignments, women still encoun- ter hardships to exercise control over their own bodies in their sexual life; their agency is much lower than men's in managing sexual health risk, a gender-specific depending on their femininities' overall pictures. Gendered vulnerability to HIV infection, with women being most at risk, is globally acknowledged. Chinese official reports admit that 'sexual transmission within marriage poses a great threat to women' (National Center for AIDS/STD Control and Prevention 2010) with 31.7\% of women becoming infected through the heterosexual route by spouses/regular partners. This figure contrasts sharply with that of men $(6.8 \%)$. It is also found that more women than men tend to disclose their HIV status to their new sexual partners. While sexualities in their diversity are widely acknowl- edged, sexual health and sexology-oriented discourses in the health and social sciences spheres still reflect an overarching medical science and essentialising view (Micollier 2005, 2012a; Evans 2008): gender stereotypes are prevalent in both expert and lay discourses. Preconceived ideas about, and stigmatisation of, people who have sexual activities other than heterosexual are still widely shared in the population at large.

In 2007, the first large-scale survey on HIV and AIDS-related knowledge, atti- tudes, behaviour and practices with 6382 participants was conducted in six Chinese cities, including Beijing and Shanghai. Although most people correctly identified sexual transmission as one way of contracting HIV, the lack of proper risk assessment and lack of knowledge of preventive measures cause individuals to continue 
to engage in high-risk behaviours. In regard to condom use, for example, $29.6 \%$ of respondents did not know how to use one correctly, $43.1 \%$ had never used one and only $19.2 \%$ said they would use a condom if they had sex with a new partner. As well, low awareness and the stigma associated with HIV and AIDS inhibited their seeking knowledge: $83.4 \%$ had never sought information on HIV and AIDS on their own initiative and 57\% had never talked about HIVrelated issues with their family members, friends, classmates or colleagues (CHAMP 2008). While the ideals of masculinity have informed men's engagement in high-risk behaviours (e.g. multiple sexual partners and unprotected sex), 'womanhood' and 'femininity' construction has greatly constrained women's control over their sexual life, includ- ing the use of safer sex practices. In summary, HIV and AIDS is de facto a deeply gendered and sexualised issue in China as it is elsewhere. Significantly, most of these findings from the 2008 CHAMP survey are revealed in multiple actors' dis- courses, either lay (popular understandings of gender and sexuality), official (in relation to governing men and women in society), or medical (the role of medical and scholarly discourses and either scientific or traditional knowledge in gender narrative construction). They are related to the way women and gender roles are still 'imagined.' However the understanding of sexual and gendered narratives about HIV and AIDS is still limited (Micollier 2012a).

Drawing on interview data from a larger empirical study on transnationalism and HIV gendered vulnerability, this article examines the intersection of gender norms and roles, femininity and HIV risk in the context of trans-cultural spaces through the narratives of Chinese immigrant women to Canada. I first introduce the conceptual framework, which is informed by normative landscapes of femininity in China past and present, and by the theoretical interconnection between gender and transnationalism. Secondly, I describe the methods of the larger study, along with the analytical approach used in interpreting the data and the aims of the spe- cific study that are the focus of this article. In the findings section, I examine family relationships and intimate spaces of women's experiences, and gendered HIV risk, paying close attention to the mapping of femininities on transnational journeys.

\section{Conceptual framework}

Femininity in China can be explored, from an historical perspective through the interconnected notions of family/jiating (家庭) and State/guojia (國家): Jia 家 shared by both terms means 'family, household, home'. Femininity can also be unveiled through contemporary constructions of gender norms and roles. The latter include women's sexuality legitimation and moralisation by the institution of heterosexual marriage. Social norms involving femininity operate at various levels intersecting with each other - the individual, family, society and the State. Views on womanhood and sexuality together constitute a relevant entry point for under- standing genderrelated issues and femininity. Sexual and intimate relationships 
are embodied experiences embedded in a complex weaving of individual emo- tions, feelings and desire, and social relations and processes.

In Imperial China until the eighteenth century, before the all-pervasive encoun- ters with the West in the nineteenth century, the State structure and power dynam- ics in political and social relationships mirrored family structure and relationships through patriarchal, hierarchical patterns, and gendered relational attributes and values. The terms used in official discourses over time reflect gendered power relations, norms and roles. Chinese women/funü(婦女) literally 'kinswomen' is a kin-inflected category (Barlow 1991) locating women exclusively in the family; funü was used in Imperial China and introduced again in the official discourse in Maoist China as a modern State category (Barlow 1991), redefining 'women's' main role in relation to the State and the family. Early Republican China (1911-1928) marks a discontinuity: the 1920s modernists influenced by the West promoted a new term nüxing (女性) meaning 'woman, female sex attribute and quality' reflecting an essentialist and individual-centred view. In China, naming male/female per- sons varied through the life cycle and revealed gender roles in the life cycle of a female individual: girl/nü (女), woman/fu(婦), and mother/mu (母) refer to gender roles ascribed to female individuals in line with gender norms. Even though rapid changes in sexuality are acknowledged from the 1990s, femininity and masculinity may be still anchored in the roles of father-mother and wife-husband (Brownell and Wasserstrom 2002). These authors have called to attention key points on gen- der concepts and the construction of masculinity and femininity in China gender scholarship:

Gender concepts were anchored in beliefs about family structure and social roles more than in beliefs about biological sex ... 'men' and 'women' were plural categories rather than unified categories opposed to each other; 'manhood' and 'womanhood' were not directly linked to heterosexuality, and reproducing the lineage was a more important aspect of sexuality than individual pleasure. (Brownell and Wasserstrom 2002, 34)

In the China context, gender role models and cognitive archetypes from historical China coexist in landscapes of femininity, which are caught in between re-ascribing either the Imperial and Maoist China 'kinwoman', or the sexualised and essen- tialised individual woman nüxing inherited from Republican China and Western cultures.

In line with Foucault (1976), sexuality is a crucial site for competing power rela- tions, and discourses of sexuality help in producing, regulating and changing social orders: the mise en discours (terms in discourse) of sexuality in Europe in relation to power and control over the people also prevailed in China. To some extent, it still prevails in contemporary China through a State discourse regulating and monitoring closely sexual behaviours and meanings (Dikötter 1995), for example in relation to the HIV epidemic (Dikötter 2000). Forms of consumption and commodification of pleasure constitute perfor- mances of class and nation based on a gender difference (Butler 1990): buying women's bodies allows men to construct masculinity not just as men, but as 
Chinese men of a certain class and a certain citizenship. Nation-state construction and citizenship are a key determinant in the construction of masculinity. Participating in these entertainment activities is part of the business culture in China (Zheng 2009). Micollier (2004) discussed gendered power dynamics at work in the marriage institution, family relationships, and the role played in these by extra-marital sexual exchanges for money and gifts. Marriage rules and women's traditional roles were prescribed within the model of a 'Confucian family' promoted by the State, in which sexual norms and values include heterosexuality, connubial- ity, intimacy, and value of sex for reproduction over pleasure. In dialectical relation with these 'explicit' norms, sex work and extra-marital relationships constitute an 'implicit' norm. From the 1990s when China entered the globalising consumerist culture with the emergence of large middle classes, sexual life became a marker of gender categorisation (Evans 2002, 2008; Micollier 2004). The locus of gender production changed from the family to heterosexuality and hetero-normativity.

While transnationalism studies focus on the multi-stranded relations built by people between places of destination and origin (Levitt and Glick-Schiller 2004), from the mid-1990s they aimed at developing work on gender, migration and glo- balisation (Yeoh and Ramdas 2014). Gender approaches unveil the links between social reproduction and intimate aspects of life. Transnational mobility is often 'a pervasively masculine construction where women participate not as economic agents but as moral guardians and preservers of the family' (Yeoh and Willis 1999, 368), and gender is acknowledged as: 'a central organising principle in migration flows and in the organisation of migrants' lives' (Lutz 2010, 1651). In migration patterns across national borders, embedded or explicit expectations are related to ideologies and practices of gender (Freeman 2001).

\section{Methods}

In this article, I draw on interview data collected in China and in Canada among Chinese immigrant women to Canada. These women were participants in a qual- itative study titled (Living in Transnational Spaces: Gendered HIV vulnerabilities of Chinese immigrants in Canada) that was conducted in China and in Canada from 2011 to 2015. Study data were collected through individual, semi-structured, in-depth interviews carried out in Beijing, Shanghai, Toronto, and Vancouver, with 66 immigrant adult individuals, 31 women and 35 men. Most of them arrived in Canada from China in the 2000s, and currently live in Canada or China. Their ages ranged from 21 to 58 years with an average age of 36.7 years. Eligible informants had lived at least one year in Canada and claimed to have maintained close con- nections with China. While recruitment in Canada was through Chinese community networks, Chinese community media including the Internet and word of mouth, participants in China were mainly recruited through the personal networks of Chinese team members. While the ages of the 31 women ranged from 21 years to 54 years, the majority were in their $30 \mathrm{~s}$ and $40 \mathrm{~s}$. Half of them were permanent residents; 
the others were (naturalised) citizens, except one who was an international student. Among the 31 , one third were single, one third were married, one third were separated or divorced, and one was living common-law. Most women identified themselves as heterosexual. The majority had travelled to China after immigration to visit families, while a few returned for work, vacation or vocational training. Among those who were married, half of them lived in 'transnational families'. Transnational families are those in which spouses live separately most of the time, revealing paradigmatic situations of transnational life. Women with transna- tional families are middle-aged women ranging in age from 38 to 53 years. Their level of education is high, all having attained at least an undergraduate degree. They work full-time, except one who is selfemployed, and another one who is unemployed, and are all permanent residents of Canada. They often communicate with their husband, who frequently travels in China, through ICTs, but they often do not see their spouses for long periods of time.

In regard to providing evidence in this article, I use the rationale of 'thinking in cases' (Forrester 1996) as a methodological heuristic. Hacking (1990) posits that there is no single style of reasoning in sciences; indeed, there are several styles of reasoning. Hacking suggests six styles of reasoning: postulation and deduction; experimental exploration; hypothetical construction of models by analogy; ordering of variety by comparison and taxonomy; statistical analysis of populations'regulari- ties; and historical derivation of genetic development. In addition to these, Forrester (1996) points out another one, namely 'reasoning in cases', whose operative context could be psychoanalysis and related disciplines. Based on narratives as the main eth- nographic material to unveil intimate spaces of the person, the operative context is indeed related to a social and psychological anthropology, which can be considered a related discipline. Hence, using this analytical approach in interpreting the data, I dig out material from three selected 'cases': the life stories of three women living in transnational families, namely Ms Liu, Ms Huang and Ms Wang, aim to highlight paradigmatic situations. This contextualized perspective provides a better and more in-depth understanding of the situation of women's living in transnational spaces. Simultaneously, I purposely go back and forth from the whole sample (31 women) toward a focus on their three life stories to highlight commonalities or differences.

I selected these three women's narratives using three criteria: the first one is operational, namely women living alone most of the time as a mother and spouse, and with a unique child in transnational families; the second is methodological referring to the biographical method widely used in social anthropology; the third one is genealogical: all the files available from women's narratives screened through Nvivo qualitative data analysis software were considered. In the study, Nvivo software was used for content analysis, which helps in framing major thematic codes and sub-codes. 'HIV risk' and 'Gender, sexuality, family relations' major codes data-sets highlight that among the 31 women, these three women, Ms Liu, Huang, and Wang extensively quoted throughout the article, provided together a whole conversation rather than fragments about their experiences. 
From this finding, I decided to dig out their complete life story through all their narratives available in the complete data-set. This biographical method is indeed a tool to unfold the various layers about femininity, sexuality, and HIV risk in transnational context, and their complexity with contextualized situations.

In the following discussion about the findings, pseudonyms are used to respect the confidentiality of participants' views and identities.

\section{Gender, sexuality and family relationships in transnational families}

Gender norms and roles, family and intimate relationships, women's role assig- nations through the life cycle (girlhood, womanhood and motherhood) are key domains in which to explore femininity. In Mainland China, in the past, conjugal links to the patriarch would define all the family relations. Nowadays these links and individual affirmation are more powerful in family relationships in China. Yan (2009) studied the individualisation and privatisation process in intimate and family relationships over time from the Reform Era period (post-1979) noticing the increasingly important role of the conjugal link in the family, and even in rural China (Yan 1997). Changes in conjugal relationships and power dynamics at work in the family are a relevant thematic line for studies of Chinese (skilled) immigrants in general, and our study in particular. In study data, a number of interviewed men and women were divorced or separated. For some, the dynamics of divorce/separation diverge from those in China, as most were middle-aged, while in China most divorcees are found in the young generation. This difference could be related to their level of education and socio-economic status before migration. Settlement difficulties were salient for men in Canada, a number of whom, subsequently decided to go back to China. These difficulties usually generate conflicts within marriage, a common situation among Chinese skilled immigrant families (Zhou and Coleman 2011). As a result, the wife often stays in the host society (Canada) with the children, and the husband returns to China, travelling back and forth. In the women's narratives, however, the situation is much more complex than expected, and revealing of what it means to live a transnational life. Women were able to speak out about their feelings of sadness and loneliness related to their situation of living in transnational families. However, in their own words, they would not move on to change this situation.

For them, separation is part of transnational family, life and marriage.

Ms Liu, Ms Huang, and Ms Wang are mothers living in transnational families and at the time of the study, with their only child. Ms Liu and Huang live in Canada while Ms Wang went back to China. Ms Liu had moved to Canada two years before she was interviewed. She is in her 40s, has a high level of education, and holds a university teaching position in China. She is based in Canada with her pre-teen daughter (aged 12). Her husband lives in another Western country most of the time, making business trips in China. When she moved to Canada with her daughter, he was already based abroad. She moved to Canada to take a three-year contract position. 
She has daily email and telephone contact with colleagues in China as well as students there whom she supervises. She calls her family and relatives for Chinese New Year and other holidays. She admitted that China still has a powerful influence on her. Ms Liu's husband has visited them: ' 4 times a year for more than 3 years, and all together only over one month for the past year.' She expressed her feelings as follows: 'I feel the separation is too long, I feel sad. I am really sad, no relatives, no friends, no close friends. It's a big problem ... I contact my husband very often, but he is busy.' Sticking to gender norms and showing a conservative attitude, thereby valuating womanhood construction as a spouse, she affirms: 'I am very faithful, I don't have any relation out of marriage relationship.'

At the time of her interview, Ms Huang had been in Canada for 23 years. She is in her 50s and lives with her 21-year-old daughter. Although she holds a uni- versity degree, she is unemployed. Her husband of 30 years works in China. She still has close contact with China. She revealed that her husband had changed before immigration. This is something that she has come to accept: 'In fact, we were university classmates ... But people are always changing, the society is also changing ... He changed more than I did ... the recent 10 years.'

She feels that her husband changed because he became rich and she hints that wealth and his business lifestyle have created opportunities for infidelity:

If you do business, you have many social occasions. Also if your business is going well, you will encounter all kinds of people ... I feel the tendency is, as your fortune increases, the temptation you are facing increases.

This raises her concern about the security of her marriage and her sexual health: 'I have always concern about my marriage. I have concern about my health, the two are equal'. She worries about the sexual risk, including HIV risk, she may take while having sexual relations with her husband. He does not practice safer sex with her and she acknowledges that he may have, in her words, 'unsafe behaviour.'

In both Ms Liu's and Ms Huang's narratives, one can observe static views on gender norms. In Ms Huang's case, she accepts her husband's infidelity and his control of the distribution of the family fortune and income. Ms Liu feels acutely her family duty towards her elderly parents and parents-in-law. She feels caught between commitment to her job in Canada and family duties in China towards elders and her husband. Her pre-teen daughter wants to move abroad because she had many classmates from China doing so. In Ms Liu's words, her 'husband had to come since it was for the whole family'; however he did not move to Canada until now. The tension between motherhood and womanhood is acute in Ms Liu's and Ms Huang's narratives. Ms Liu wants her daughter to stay in Canada 'for school.' However, she knows that she cannot extend her position in Canada beyond three years. She thinks about going back to China alone. Ms Liu's narrative reveals the importance for her of motherhood and family duties as a daughter, daughter-in- law, and spouse. 
As for Ms Huang, motherhood 'sacrifice' is, in a dialectical way, detrimental to womanhood expression and well-being: 'I have to stay here as long as possible, because my daughter is single, I can be her company, I should sacrifice myself.'

Ms Wang lived in Canada for five years, before returning to China with her 3-year- old son because she felt life in Canada was very boring. She returned first and her husband after. She lived in China alone before moving to Canada and after returning to China. She still visits Canada and the US during holidays to see her friends. Before immigrating, she had a good job in China in the media and a successful social life. Her narrative reveals views that diverge from those of Ms Liu and Ms Huang, and from most women in the study data, on sexual life, extra-marital relations and HIV perception and all HIV-related issues. Despite this, she claims to stick to traditional views on gender norms and roles:

A woman will only have sex with a man if she has feelings for him ... Actually there are a lot of one night stands. I have a lot of friends that do that.

Interviewer: Have you had this experience? No, I am very traditional.

While discussing 'one night stands' she adds: 'I am the type that is very rational. I won't do anything just based on my emotions'.

In her view, which proves not as 'traditional' as she declares, a woman assesses the level of risk from how she feels:

You still need to have protective strategies, so you can still have a one night stand ... It is not just to prevent AIDS, it is also to prevent pregnancy or other hurts. No one wants to experience an abortion.

Interviewer: Yes. One is to prevent pregnancy; the other is to prevent illnesses. Yes. This will depend whether you will protect yourself or not.

Her claimed rationality reflects a pragmatic view about practising safer sex for both contraception and prevention of STIs. Her stance takes her very far away from her claimed 'traditional' views. These contradictions unveil a gap between how she characterises herself, namely as a traditional woman, and her sexual life and views on practising safer sex, give a fluid, complex and paradoxical sketch of femininity. Ms Wang chose to be suggestive and not declarative on her own sexual life. Her suggestive narrative is a way to both express her femininity and 'live' gendered power situations, as well as a pragmatic way to negotiate them. She experiences tensions between her views on gender norms and her own behaviour diverging from them. Ms Wang is indeed caught in between 'living and cognising gender' (Micollier 2012b): in her own way she positively mitigates these tensions.

In regard to their femininities' mapping, these women's narratives reveal a range of, and eventually interlocking set of, ideas and practices related to sexual and intimate life, gender and family relationships. The felt and expressed ambiguities in their gender roles are more acute in the context of their transnational family life experience. Although these women view themselves as traditional in regard to their gender roles, and their discourse often reflects clearly static gender norms, they may behave differently in practice. 
They express tolerance and understand- ing for those who do not share the same views: this observation can be partly explained by their transnational experience in Canada, namely the confrontation of gender norms and roles from another culture.

Motherhood finds a strong grip in their life and womanhood aspirations are left behind. Most women experienced downward socioeconomic mobility with migration, deterioration of selfesteem, instability in their life conditions, uncer- tainty about the future, and acceptance of physical separation from their spouse and loneliness in their marital relationship. That they are caught in-between China and Canada is a key aspect of the transnational life they experienced, a social and psychological reality, which needs to be unfolded layer by layer.

The women's narratives highlight a diversity of ideas and situations relative to gender norms, family and intimate life in a transnational context, and close, almost daily, transnational connections. Their condition of usually living with their children has implications for their expression and construction of femininity, and the way of living motherhood and womanhood. Pluralist meanings and the diversification process of ideas and practices related to family and intimate relations have greater salience in a transnational context, following the immersion in another culture while being still anchored in the other. Therefore, this diversification pro- cess already observed in Chinese societies, deepens in the context of transnational experiences. Not surprisingly, a more flexible attitude may prevail in a new life situation regarding the code transmitted through the culture of origin. However, negotiations in the inner self are often at work in situated contexts of the new life. The cognitive, affective, and emotional landscape shaped during the socialisation phase in China, may explain this deep contradiction for all those who are not born in the other culture.

Ms Huang in contrast to Ms Liu and Ms Wang is unemployed, and accepts an economic dependency, namely to rely on her husband's wealth. For Ms Liu and Ms Wang, commitment to professional duties is in tension with family duties. Women's narratives highlight that gender power relationships work differently for skilled women. As most women in their postimmigration lives, Ms Wang had experi- enced socio-economic downward mobility. For a number of reasons including the opportunity to regain an upward socio-economic status, she decided to go back to China. Among skilled women immigrants, there is no obvious connection between economic independence, socio-economic status, and their femininity's landscape including their views on gender norms and roles.

\section{Intimate feelings, power relations and gendered HIV risk in transnational life}

In the women's narratives, sex work and extra-marital relationships are recurrent topics. Men buying sex and putting their partners at risk with respect to STIs, including HIV infection, is an extensively discussed issue among the women 
whether they are married, divorced or single. The 'unfaithful' husband is a preva- lent figure in most women's discourses. Most women who expressed their views about this issue were well aware of the sexual risk related to their husband's or former husband's extra-marital behaviour. These men may have mistresses or a second wife in China, or hire sex workers or escort girls while travelling in China or elsewhere for business. As noted earlier, men's participation in the sex industry is a part of the business culture in China and important in the construction of masculinity. In addition, gendered mobilities and transnational flows are shaped by the international job market and facilitate the development of extra-conjugal relationships in general, and more specifically for those living in transnational families. Migration is a well-known gendered risk factor for STIs including HIV infection in China (Micollier 1998; Yang and Xia 2006).

Ms Liu speaks out about her husband buying sex and the issue of safe sex. In a discourse loaded with implicit significance, she reports about a friend who 'got fungus':

... she worried about her husband, because he is very different from mine. He goes on many business trips in China. He is away from home a lot of time, and her husband is a very open person, so she worried about it ... She never uses condom with him.

Commenting on her own situation, she observes that: '... All husbands, my husband does not like to use this thing. Most men don't like to use it.'Although she worries, she feels she can do nothing about it, showing a lack of agency and empower- ment in risk management while she perceives acutely the risk of unsafe sex: 'For this, women are not dominant ... I don't know about other people, but for me and my colleague, she and I both listen to our husbands'. She thinks that as a wife she should be submissive: 'In China, women and men seem to be equal in many aspects, but, in fact, in this aspect it seems to be unequal.'

As the interview unfolds she goes on to mention business trips taken by her own husband to another country:

... more open there, things like strip shows, he has watched. He went there with col- leagues. Because his company has many Chinese colleagues there, when there are guests from China, they bring them to these places ... I don't like that. I told him not to go, but he said it's impossible. Their guests from China have a list, you have to go with them. The list has a schedule for all the activities.

She is aware there could be unsafe behaviour:

I think there is, I am afraid there is ... I asked him, but he said absolutely no ... I am curious that when they watch this kind of show, don't they feel anything? So I worried. I worried about being infected by other people, for example I worried about my husband because he is not myself ... others pass it to me through my husband, I have no way to know. When I am having sex, I worried about STD, HIV, and AIDS, etc.

Ms Liu evokes her 'transnational' conjugal situation and her husband's attitude toward condom use:

... unlike couples who are together every day, this kind of separation makes it like this ... if I talk to him, he would say I am suspicious about him. I can't ask him to use condoms 
... I bought condoms shortly after I gave birth to my child. Did not use them. At most, used it once, he does not like the trouble of using it. Did not use it, what I said to him is in vain. It hurts feelings!

She attributed her husband's attitude, wives' lack of agency in sexual relations, and gender inequality to Chinese culture:

Chinese men, they are very male centred ... [her husband] does not care about what women think ... I feel in China, it hurts feelings, it means you don't trust him, so you ask him to use condoms to prevent STD ... Can't talk too much [about that]. There is no negotiation on using condoms. There is inequality between men and women related to Chinese culture for sure.

Ms Huang described the situation with her husband as follows:

He had many opportunities to make a new choice. He became rich, a while ago not just today. I think the second wife, the third person ... But for this kind of temporary sexual behaviour. I don't think my husband is an unfaithful person.

Even though her husband's extra-marital experiences may be considered as infidel behaviour, she does not perceive him as an unfaithful person. However she worries about sexual health risk and feels 'she can't control':

She [a potential second wife] knows [that I] am not there, also knows [I] can afford that ... She has been working with my husband ... not married, this is an unsafe factor ... Another friend said that marriage is the tomb of love, the little third person still wants to dig the tomb.

In the end, she admitted that she feels sad and that she is afraid of losing face in this situation, unveiling mixed feelings of being caught between understanding and tolerance on the one hand, and anger, deep disappointment, and wounded self-esteem on the other:

I am faithful to my marriage, but I need to solve the problem, I am human. The problem is that he is also human, not that because I am in Vancouver, he is no longer human?

She also expressed her feelings regarding menopause, revealing a traditional view: ' $I$ feel sex is something I can live without...sex function is deteriorating'. Ms Huang's narrative reflects an ambivalent attitude towards her husband's unfaithfulness. Her rather tolerant attitude is in a dialectical tension with deep worry regarding sexual risk and cynicism about an intimate relationship situation where there is at least 'a third little person.'

Ms Huang's narrative concerning her husband's extra-marital affairs is related to cultural and social norms for men and women in China: she has a save-face attitude which may be interpreted as a denial attitude from a psychological viewpoint. However extra-marital affairs for men are a 'distinction marker' in a Bourdieusian sociological lens in historical and today China (Micollier 2004). Simultaneously, Ms Huang may have mixed feelings at an intimate level and a positive view on her husband at a social level. He is rich and holds a high social status, which may be gratifying for her as her spouse: extra-marital affairs are indeed status attributes according to gender norms for men. 
Women's narratives unveil feelings and emotions common in post-immigration lives of women: intimate feelings of worry, anxiety, sadness, loneliness and love. All of these are relevant for understanding femininity. Self-esteem and femininity are engaged negatively for them. They share mixed feelings about love, sexuality, and changes at individual and societal levels. In contrast, Ms Wang reported having no problem using condoms while having sex with her husband, revealing a strong and rare sense of empowerment in her own sexual life: 'I feel that I need to use con- doms at all times. No matter with whom I am ... then I need to use condoms even if I am with my husband'. Her awareness about protection is strong. She has very good knowledge of HIV-related issues through the work she was doing in Beijing before moving to Canada. She used to report about these issues, contributing to the advocacy efforts of her employer.

However, her narrative still reflects traditional behaviours and views in regard to extra-marital relations. Her claim for the woman and mother roles conforms to traditional gender norms. Nonetheless her transnational life is not a distressful experience to be endured, as it is the case for Ms Liu, Ms Huang, and most women participating in the study. Married women's vulnerability to sexual HIV risk and transnational conjugality are more intimately understood in relation to key com- ponents of common masculinity's landscape such as buying sex in the business culture, a distinctive benchmark of social status, unsafe risk behaviour and aware- ness of HIV risk. Their lack of agency in sexual exchanges regarding condom use is repeatedly underlined.

As acknowledged by Ms Liu, Ms Huang, and Ms Wang, and by most married women or women who had been married, their husbands remain or become more mobile because they commonly experience downward social mobility. They live separately from their spouses at times or most of the time. They do business trips in China, and sometimes resettle in China. Immigrant women may also experience downward social mobility. However, this situation usually does not produce the same consequences for marriage and family life because of gender power relations and dynamics at work in this context. Living in transnational families increases the risk to the sexual health of both men and women as long-term separation is the norm rather than the exception. STIs including HIV risk was acknowledged by most interviewed women. Their knowledge and perception of HIV risk is average; engaging in unprotected sex in situations that they understand to present risk is acknowledged by one fourth of them.

HIV risk management in their transnational experience is deeply gendered: while a number of women in the data have knowledge and awareness of risk, they feel powerless in coping efficiently with it because of gendered power rela- tions stemming from gender norms such as gender inequality in family relations and sexual life, and the value of a wife's submissiveness in sexual relations. Even though women can perform different forms of heterosexuality in their post-im- migration lives, they'come across challenges and obstacles to their performances of heterosexuality, such as the state regulation of the migrant body, economic 
necessity, and gendered and ethnicised behavioural norms' (Walsh, Shen, and Willis 2008, 575). In accordance but also in contrast to most economic migrant women, the performances of skilled immigrant women to Canada are challenged by the Chinese and Canadian states' regulation of their own bodies, as well as by gender norms of both home and host societies in the processes of migration and self-transformation through experiences in situ over time. Nonetheless they are not challenged by economic necessity.

In the women's narratives, individual affirmation and claim for economic inde- pendence are indeed found although in most narrated situations, their attitudes and aspirations remain in tension with the traditional way of securing a comfort- able life for themselves. Once again this traditional way unveils deeply gendered power relations.

\section{Discussion}

The article's focus was to discuss femininity and transnationalism through narra- tives on gender norms and roles, family relationships and sexual health risk with a focus on HIV among Chinese women immigrants in Canada. HIV risk is understood in connection with experiences of extramarital sex including sex work, and views on, and practices of, safe sex including condom use.

A gender perspective helped in showing how migrants developed gender-spe- cific transnational lives; was used to unfold gender norms and roles, and for an overall mapping of femininities. These latter were informed through women's nar- ratives about their experiences on sexuality, intimate and family relationships. Gendered power relations and HIV vulnerability were discussed in the context of their transnational life. However the vulnerability paradigm was recently chal- lenged with studies acknowledging that:

Women and men may be infecting each other in far more balanced numbers than the vulnerability paradigm suggests ... it retains a focus on men as participants in a system of gender inequality but also acknowledges how men's HIV risk, like women's, can be heightened through gender and structural inequality. (Higgins, Hoffman, and Dworkin 2010, 441)

As an example supporting this new development, our study confirms that a num- ber of women and men engaged in open sexual relationships, and that gendered power relations and gender inequality impact both men's and women's HIV risk. Studies conducted in Africa show that women usually underreport about their multiple partnerships (Higgins, Hoffman, and Dworkin 2010, 439): findings from our transnational Chinese case undoubtedly adds support to these. However, addi- tional research is still needed through other studies in various contexts for further challenging of the gendered vulnerability framing.

Tensions at work regarding the issue of economic dependence for married women are reinforced when some members of the family live far away from other members and from native locality. In the context of immigration, this 
process increases de facto the centrality of conjugality and the influence of the Western-origin nuclear family model in family relations. These influences remain in tension with the nature of gender inequality in the context of Chinese culture: this inequality is structural in both the Confucian-oriented model of family rela- tionships with its highly gendered set of values and the Chinese society's social organization.

Among skilled immigrants women, dynamics of gender power relations are still not working in favour of women's agency in sexual relations and sexual risk management in most conjugal situations. Interestingly enough, such agency is not systematically connected with their economic independence, and even though skilled women are usually aware of the on going male dominance and speak out easily about gender inequality.

The so-called 'traditional' values may be 'invented' as pointed out by Johnson, Jackson, and Herdt (2000) in discussing the status of 'Asian values' among people who have immigrated out of Asia; their behaviour may actually be in structural tension with these values while looking at their lifestyles and their contradictory aspirations with respect to these. However, in line with Yeoh and Willis's (1999) study, women' narratives in the study shed light on their gender roles as guardians of a moral and social order grounded in Chinese culture rather than as economic participants and empowered agents of their own life. In their transnational femininity's mapping, these roles remain a key aspect as they reveal gender as a main organising principle in their postimmigration lives. In line with Waters's (2002) study, Chinese and Canadian states play a role in the gendered process of migration and settlement. In contrast to her study, wives may move back to China (Ms Wang) and their husband may work and live in a 'third' country (Ms Liu); both men and women may experience divorce or separation. Family situations and relations are much more diverse than those described in Waters's (2002). Indeed all wives participating in her study live in an 'astronaut' family, a family where typically the husband moves back to Asia and the wife and their children settle down in Canada, the host country. All women informants were unemployed, experienced economic dependence and downward social mobility. In terms of highly gendered pattern commonly identified in the migration process, according to the women participating in our study, childcare responsibilities and unemployment impacted negatively their feeling of self-esteem; they experience downward social mobility. These issues were mentioned as part of their settlement difficulties. These results contrast with those of Waters's: 'the vast majority of participants did not perceive many of the indicators of gender oppression, such as child care responsibilities and lack of employment as oppressive' (Waters 2002, 125). In a more recent work (Waters 2010), the 'astronaut' family experience is described from another actor's perspective, the 'astronaut' parenting husband: gendered power relations typically highlighting male domination are eventually reconsidered. Indeed in the end, men 
like women experience emotional distress, difficulties of settlement, dependence and unemployment.

In our study, women's narratives reflect a diversity of ideas, practices and situ- ations related to sexuality and family relationships and a more salient agency at the individual level in decisionmaking and conjugal relations. Most women were either divorced or geographically separated from their husbands. A number of them engaged in relatively open sexual relationships: their 'secret lives' may be unveiled in their narratives.

These experiences are difficult to speak about for them because they claim and are supposed to behave according to their culture of origin's gender norms. Traditional gender norms and relationships are challenged because these women experience downward mobility, settlement issues, geographic separation, and changes in their conjugal relationship. They also experience emotional distress, including loneliness, sadness, jealousy, and isolation. Sexual health risk and vul- nerability to HIV infection are more salient for women who are divorced or married and geographically separated from their spouses most of the time, namely those living in 'paradigmatic' transnational families.

The conditions of these skilled women's post-immigration lives have implica- tions for their femininity and their sexual health risk. The sexualised and essen- tialised individual woman (nüxing) and the kinwoman (funü) perform together in subtle and fluid arrangements in intimate and social transnational spaces. The immigration experience of women participants in the study has transformed their femininity unraveling the 'jiating-guojia' nexus linking closely family, marriage, and the State, from both old and 'new' socialist China. The landscapes of their femininity are thus constantly evolving: indeed, the stabilised shapes and forms of these depend on their life experiences on the long-term.

\section{Acknowledgements}

The author wishes to express her appreciation to the research participants of this study in both Canada and China. I cheerfully thank the research project P.I, Professor Yanqiu Rachel Zhou and Nancy Johnson for their help in the article's finalisation. I am also grateful to this project's research associates and assistants, Dr Helen Hong Su, Liping Peng, Emmy Arnold, Dr Xiaoqing Gao, Xiaoxin Ji, and Jane Ma, and collaborators (Chi Heng Foundation, Shanghai, China; Institute of Sexuality and Gender, Renmin University of China; Asian Community AIDS Services, Toronto, Canada; St. Stephen's House, Toronto, Canada) for their contributions at different stages of this study. Finally I thank the two anonymous reviewers for their insightful comments and suggestions.

\section{Disclosure statement}

No potential conflict of interest was reported by the author. 
1804

\section{Funding}

This work was supported by Canadian Institutes of Health Research [grant number 111081]; McMaster Arts Research Board Scholarly Publications.

\section{Notes on contributor}

Evelyne Micollier is a tenured research scholar at the IRD (French National Research Institute for Sustainable Development); a corresponding fellow for China at IrAsia (Institute for Research in Asia, CNRS-Aix-Marseilles University, France); a corresponding fellow at IdG (Institute for Gender Studies), Paris. With degrees and experience in three academic disciplines (PhD Social Anthropology, MPhil Chinese Studies, Guangzhou University degree in Traditional Chinese Medicine), she is conducting long-term research at the intersections and interstices of these domains. Currently stationed in Lao PDR, E. Micollier is developing projects in South-East Asia and in Greater China (including transnational China). She has participated as an investigator in the project 'Living in Transnational Spaces: Gendered HIV vulnerabilities of Chinese immigrants in Canada' (2011-2015), McMaster University. She recently published articles on gender, sexuality, body knowledge and practice, and on knowledge production, co-construction, and circulation (pharmaceutical innovation, medical research in Chinese medicine; dissemination and globalisation of Chinese medicines, research ethics and ethno-ethics).

\section{References}

Barlow, Tani E. 1991. "Theorizing Woman: Funu, Guojia, Jiating (Chinese Woman, Chinese State, Chinese Family)." Genders 10: 132-160.

Brownell, Susan, and Jeffrey N. Wasserstrom, eds. 2002. Chinese Femininities, Chinese Masculinities. A Reader. Berkeley: University of California Press.

Butler, Judith. 1990. Gender Trouble: Feminism and the Subversion of Identity. New York: Routledge.

Carling, Jorgen. 2005. The Gender Dimensions of International Migration. Paper No. 35. Geneva: Global Commission on International Migration.

Castles, Stephen, and Mark J. Miller. 1993. The Age of Migration. International Population Movements in the Modern World. Basingstoke: Macmillan.

CHAMP. 2008. AIDS-related Knowledge, Attitudes, Behaviors, and Practices: A Survey of 6 Chinese Cities. Beijing: UN Publications.

Dikötter, Frank. 1995. Sex, Culture, and Modernity in China: Medical Science and the Construction of Sexual Identities in the Early Republican Period. London: Hurst. 
Dikötter, Frank. 2000. "La sexualité et les maladies sexuellement transmissibles en Chine: discours médical et représentations sociales [Sexuality and STIs in China: Medical Discourse and Social Representations]." In Sociétés asiatiques face au sida [Asian Societies Confronted by AIDS], edited by Marie-Eve Blanc, Laurence Husson, and Evelyne Micollier, 23-39. Paris: L'Harmattan.

Evans, Harriet. 2002. "Past, Perfect, or Imperfect: Changing Images of the Ideal Wife." In Chinese Femininities, Chinese Masculinities. A Reader, edited by Susan Brownell and Jeffrey N. Wasserstrom, 335-360. Berkeley: University of California Press.

Evans, Harriet. 2008. "Sexed Bodies, Sexualized Identities and the Limits of Gender." China Information 22 (2): 361-386.

Forrester, John.1996. "If $p$, ThenWhat? Thinking in Cases." History of the Human Sciences $9(3): 1-25$.

Foucault, Michel. 1976. La volonté de savoir. Histoire de la sexualité [History of Sexuality]. Vol. 1. Paris: Gallimard.

1805

Freeman, Carla. 2001. "Is Local: Global as Feminine: Masculine? Rethinking the Gender of Globalization." Signs: Journal of Women in Culture and Society 26 (4): 1007-1037.

Glick-Schiller, Nina, Linda Basch, and Cristina Blanc-Szanton. 1992. "Transnationalism: A New Analytic Framework for Understanding Migration." In Towards a Transnational Perspective on Migration: Race, Class, Ethnicity, and Nationalism Reconsidered, edited by Nina Glick-Schiller, Linda Basch, and Cristina Blanc-Szanton. Annals of the New York Academy of Sciences 645: 124.

Hacking, Ian. 1990. The Taming of Chance. Cambridge: CUP, U.K.

Higgins, Jenny A., Susie Hoffman, and Shari L. Dworkin. 2010. "Rethinking Gender, Heterosexual Men, and Women's Vulnerability to HIV/AIDS." American Journal of Public Health 100 (3): 435-445.

Levitt, Peggy, and Nina Glick-Schiller. 2004. "Conceptualising Simultaneity: A Transnational Social Field Perspective on Society.” International Migration Review 38 (3): 1002-1039.

Lutz, Helma. 2010. "Gender in the Migratory Process." Journal of Ethnic and Migration Studies 36(10): 1647-1663.

Johnson, Mark, Peter Jackson, and Gilbert Herdt. 2000. "Critical Regionalities and the Study of Gender and Sexual Diversity in South East and East Asia." Culture, Health, Sexuality 2 (4): $361-375$. 
Micollier, Evelyne. 1998. "Mobilité, marché du sexe et de la drogue dans le contexte de l'épidémie du VIH-SIDA en Chine du Sud [Mobility, Sex and Drugs Market in Times of HIV and AIDS in South-China]." Migrations et Santé [Migrations and Health] 94 (95): 55-82.

Micollier, Evelyne. 2004. "Social Significance of Commercial Sex Work: Implicitly Shaping a Sexual Culture?" In Sexual Cultures in East Asia. The Social Construction of Sexuality and Sexual Risk in a Time of AIDS, edited by Evelyne Micollier, 3-22. London: Routledge.

Micollier, Evelyne. 2005. "AIDS in China: Discourses on Sexuality and Sexual Practices." China Perspectives 60: 2-14.

Micollier, Evelyne. 2012a. "Sexualised Illness and Gendered Narratives: The Problematic of Social Science and Humanities in China's HIV and AIDS Governance." International Journal of Asia-Pacific Studies 8 (1): 103-124.

Micollier, Evelyne. 2012b. "Sexualités et intimités à l'épreuve du genre en Chine: quelques réagencements de normes et de valeurs [Sexualities and Intimate Relationships in a Gender perspective. About Re-alignments of Norms and Values]." In Chinoises au 21è siècle. Ruptures et continuités [Chinese Women in the 21 st Century. Changes and Continuities], edited by Tania Angeloff, and Marylène Lieber, 177-194. Paris: La Découverte.

National Center for AIDS/STD Control and Prevention, China CDC. 2010. Gender Analysis of Data on HIV Epidemic and Response in Six Provinces: Guangdong, Guangxi, Yunnan, Henan, Hubei and Chongqing, November 28.

Ong, Aihwa. 1999. Flexible Citizenship: The Cultural Logics of Transnationality. Durham: Duke University Press.

Povinelli, Elizabeth A., and George Chauncey. 1999. "Thinking Sexuality Transnationally." GLQ: A Journal of Lesbian and Gay Studies 5 (4): 439-450.

Statistics Canada. 2007. “The Chinese Community in Canada.”Accessed July 4,2016.http://www. statcan.gc.ca/pub/89-621-x/89-621-x2006001-eng.htm

UNAIDS. 2001. HIV/AIDS: China's Titanic Peril. 2001 Update of the AIDS Situation and Needs Assessment Report. Beijing: China UNAIDS.

Walsh, Katie, Hsiu Hua Shen, and Katie Willis. 2008. "Heterosexuality and migration in Asia." Gender, Place \& Culture 15 (6): 575-579.

Waters, Johanna L. 2002. "Flexible Families? 'Astronaut' Households and the Experiences of Lone Mothers in Vancouver, British Columbia." Social \& Cultural Geography 3 (2): 117-134.

Waters, Johanna L. 2010. "Becoming a Father, Missing a Wife: Chinese Transnational Families and the Male Experience of Lone Parenting in Canada." Population, Space, and Place 16: 63-74. 
Winarnita, Monika. 2016. "The Not-So-Gentle Makassarese Fan Dance: Misperformance Challenging Indonesian-Australian Transnational Femininity." Anthropological Forum 26 (2): 177-195.

Yang, Xiushi, and Guomei Xia. 2006. "Gender, Migration, Risky Sex and HIV Infection in China." Studies in Family Planning 37 (4): 241-250.

Yan, Yunxiang. 1997. “The Triumph of Conjugality: Structural Transformation of Family Relations in a Chinese Village." Ethnology 36 (3): 191-212.

Yan, Yunxiang. 2009. The individualization of Chinese society. London: Bloomsbury Academic.

Yeoh, Brenda S.A., and Kamalini Ramdas. 2014. "Gender, Migration, Mobility and Transnationalism.” Gender, Place \& Culture 21 (10): 1197-1213.

Yeoh, Brenda S. A., and Katie Willis. 1999. "Heart' and 'Wing', Nation and Diaspora: Gendered Discourses in Singapore's Regionalisation Process." Gender, Place \& Culture 6 (4): 355-372.

Yinger, Nancy V. 2006. Feminization of Migration. Washington, DC: Population Reference Bureau.

Zheng, Tiantian. 2009. Red Lights: The Lives of Sex Workers in Post-Socialist China. Minneapolis: University of Minnesota Press.

Zhou, Yanqiu Rachel. 2012. "Changing Behaviours and Continuing Silence: Sex in the PostImmigration Lives of Mainland Chinese Immigrants in Canada." Culture, Health \& Sexualit 14 (1): 87-100.

Zhou, Yanqiu Rachel. 2017. "'Race' and HIV Vulnerability in a Transnational Context: The Case of Chinese Immigrants to Canada." Culture, Health \& Sexuality 19 (6): 695-708.

Zhou, Yanqiu Rachel, and William D. Coleman. 2011. “'It's a Forced Separation.. and We've Got Used to This Kind of Life': Changing Dynamics of HIV Risk in the Context of Immigration.” International Journal of Migration, Health \& Social Care 7 (1): 5-15. 